\title{
Intraoperative Ultrasound as a Screening Modality for the Detection of Liver Metastases during Resection of Primary Colorectal Cancer - A Systematic Review
}

\section{(ㅇ)(우(ㅇ)}

Authors

Signe Bremholm Ellebæk, Claus Wilki Fristrup, Michael Bau Mortensen

Affiliation

Odense Universitets Hospital, Surgical Department A, Odense, Denmark

Key words

surgery, metastases, abdomen, ultrasound, intraoperative

received 22.06.2016

revised $\quad 15.11 .2016$

accepted 18.12.2016

Bibliography

DOI http://dx.doi.org/10.1055/s-0043-100503

Ultrasound International Open 2017; 3: E60-E68

(c) Georg Thieme Verlag KG Stuttgart · New York

ISSN 2199-7152

Correspondence

Dr. Signe Bremholm Ellebæk

Surgical department A

Odense Universitets Hospital

Sdr.Boulevard 29

5000, Odense

Denmark

Tel.: +45/407/76 700

s.bremholm@gmail.com

\begin{abstract}
Colorectal cancer (CRC) is one of the most common cancer diseases worldwide. One in 4 patients with CRC will have a disseminated disease at the time of diagnosis and often in the form of synchronous liver metastases. Studies suggest that up to $30 \%$ of patients have non-recognized hepatic metastases during primary surgery for CRC. Intraoperative ultrasonography examination (IOUS) of the liver to detect liver metastases was considered the gold standard during open CRC surgery. Today laparoscopic surgery is the standard procedure, but laparoscopic ultrasound examination (LUS) is not performed routinely.

Aim To perform a systematic review of the test performance of IOUS and LUS regarding the detection of synchronous liver metastases in patients undergoing surgery for primary CRC.

Method The literature was systematically reviewed using the search engines: PubMed, Cochrane, Embase and Google. 21 studies were included in the review and the key words: intraoperative ultrasound, laparoscopic ultrasound, staging colon and rectum cancer.

Results Intraoperative ultrasound showed a higher sensitivity, specificity, positive predictive value and overall accuracy for the detection liver metastases during surgery for primary CRC, compared to preoperative imaging modalities (ultrasound, computed tomography (CT) and contrast-enhanced computed tomography (CE-CT)). LUS showed a higher detection rate for liver metastases compared to $\mathrm{CT}, \mathrm{CE}-\mathrm{CT}$ and magnetic resonance imaging (MRI).

Conclusion This systematic review found that both IOUS and LUS had a higher detection rate regarding liver metastases during primary CRC surgery, especially liver metastases $<10 \mathrm{~mm}$ in diameter, when compared to US, CT, CE-CT and MRI.
\end{abstract}

\section{Background}

Cancer of the colon and rectum (colorectal cancer, CRC) is one of the most common cancer diseases worldwide and remains the second most common cause of cancer death in Western countries [1]. Approximately one in every 4 patients with CRC will have disseminated disease at the time of diagnosis and the majority of these patients have synchronous liver metastases (20\%). During the course of the disease, approximately $50 \%$ of all CRC patients will develop liver metastases, but only $10-25 \%$ of these patients may be cured by liver surgery and perioperative chemotherapy [1-3]. From a clinical point of view, it is important to know the exact extent of the disease prior to surgery. However, despite significant improvements in preoperative staging procedures (e.g., contrast-enhanced ultrasound (CE-US), multi-slice contrast-enhanced computed tomography (CE-CT), contrast-enhanced magnetic resonance imag- ing (MRI), and positron emission tomography CT (PET-CT)), studies suggest that $10-30 \%$ of patients have unrecognized hepatic metastases diagnosed during primary surgery for CRC [4-6]. During open CRC surgery, the surgeon performs manual palpation of the liver and this evaluation may be supplemented with intraoperative ultrasonography (IOUS) and contrast-enhanced IOUS (CEIOUS). IOUS has been considered the "gold standard" in open surgery for CRC since the late 1980s, as IOUS may detect liver metastases, which can neither be palpated nor detected during preoperative imaging [7-11]. Today the majority of CRC operations are performed as a laparoscopic procedure and this appears to be equivalent to open surgery regarding perioperative morbidity, mortality and oncological outcome (radical resection, recurrence rates, and long-term survival) [12-16]. The laparoscopic approach precludes palpation of the liver, but a systematic examination of the liver by laparoscopic inspection (LAP) and use of laparoscopic 
ultrasound (LUS) may be used as an alternative to digital palpation and traditional IOUS. Although dedicated probes for LUS have been commercially available for more than 15 years, LUS examination of the liver during laparoscopic resection for CRC is not performed routinely [12]. In order to assess whether standard preoperative imaging provides accurate and sufficient information regarding the presence of liver metastases in patients scheduled for (laparoscopic) CRC surgery, it is relevant to perform a systematic review of the present IOUS and LUS literature.

\section{Aim}

The aim of this study was to perform a systematic review of the test performance of IOUS and LUS regarding the detection of (unrecognized) synchronous liver metastases in patients undergoing primary colorectal cancer surgery.

\section{Method}

\section{Literature search}

A systematic electronic literature search was conducted through PubMed, Cochrane Library, EMBASE and Google Scholar and ended on the February 1, 2016. The following keywords were used: intraoperative ultrasound, laparoscopic ultrasound, colon cancer, rectum cancer, staging colon and rectum cancer, TNM staging. A secondary search was performed by manually checking the references listed in the included studies.

\section{Eligibility criteria}

English-language articles published after 1980 and containing only data on primary resection for CRC were included. The included studies were required to have a defined gold standard (i. e., histological confirmation and/or clinical follow-up). Clinical follow-up was defined as the use of postoperative imaging modalities (US, CT, CE-CT or MRI) with 3-6-month scanning intervals.

\section{Data collection and review}

A predefined form was used for data extraction and recording. The outcome data included publication year, study design, number of patients, preoperative investigation, number of liver lesions, number of patients with liver metastases, changes in treatment strategy due to IOUS/LUS, and follow-up. Clinical impact was defined as changes in the initial treatment strategy as a result of the intraoperative ultrasound findings.

The test performance (sensitivity, specificity, positive predictive value (PPV) and negative predictive value (NPV)) of IOUS and LAP/ LUS was recorded, as was the test performance of preoperative imaging modalities when available. The results of LAP alone were not reported since LUS will always include a laparoscopic inspection of the liver surface. Potential changes in treatment strategy due to IOUS/LUS findings were also noted, and a comparison with preoperative imaging modalities was performed when available.

Preoperative imaging techniques have improved during the inclusion period, and the use of multi-slice contrast-enhanced CT, MRI and PET has made conventional transabdominal ultrasound (US) re- dundant. We assume that this improved imaging would have a positive impact on test performance during the last decade of the inclusion period, and therefore we decided to divide the inclusion period into 2 periods; Period 1 (studies published before the January 1,2005 ) and period 2 (studies published after the January 1, 2005).

2 authors (SBE and CWF) independently screened all potential abstracts, selected the relevant studies and performed the analyses. Disagreements were resolved by a third party (MBM) or by consensus. The included studies were evaluated according to the GRADE guidelines [17].

\section{Results}

A total of 1677 publications were identified, but only 323 abstracts proved potentially relevant and were read. 89 articles were retrieved for detailed evaluation and assessment of the reference list ( $\triangleright$ Fig. 1). According to the inclusion criteria, 21 studies were included in the final review ( $\triangleright$ Table 1$)$.

\section{Study grading and design}

18 studies were prospective and 3 were retrospective. The overall study grading was very low. 16 articles (76\%) were graded very low and 5 articles (24\%) low. 15 studies were from period 1 and 6 from period 2 [6, 18-37]. A comparison with preoperative imaging was performed in 20 studies, whereas the impact of IOUS/LUS on treatment strategy was reported in 7 trials. The total number of included patients was 2457 , and the included number of patients varied between 13 and 388. The majority of studies had histological confirmation as the gold standard $(n=17)$ and 15 studies also included imaging based on postoperative follow-up for up to 6 months ( $\triangleright$ Table 1). 4 studies had a blinded design $(25,27,32,34)$. In 19 studies, some of the included patients had known synchronous liver metastases at the time of primary CRC surgery $(6,18-32,34$ 36). 2 studies evaluated IOUS/LUS in patients without known synchronous liver metastases $(33,37)$.

\section{Intraoperative ultrasound (IOUS)}

14 studies evaluated the test performance of IOUS in the detection of synchronous colorectal liver metastases during open CRC surgery; 10 studies from period 1 and 4 from period 2 (6, 18-25, 27$28,33-34,36)$.

\section{Per lesion analysis}

6 studies compared the test performance of IOUS to intraoperative palpation and preoperative imaging modalities in a per lesion analysis (19-22, 25, 34). In 4 studies IOUS showed a significantly higher sensitivity and a higher specificity (90-98\% and 94-98\%, respectively) compared to preoperative imaging (US, CT and CE-CT) in studies from period $1(19-22,25)$ ( $\triangleright$ Table 2 ). The sensitivity and specificity were not calculated in the only study from period 2 , but IOUS detected more liver metastases when compared to preoperative US and CE-CT (34).

The PPV and NPV of IOUS were evaluated in 2 studies from period 1 and they found a significantly higher PPV and NPV (92\% and 95-98\%, respectively) compared to US, CT and CE-CT $(19,21)$ ( $\triangleright$ Table 2). The overall accuracy for IOUS was approximately $95 \%$ 


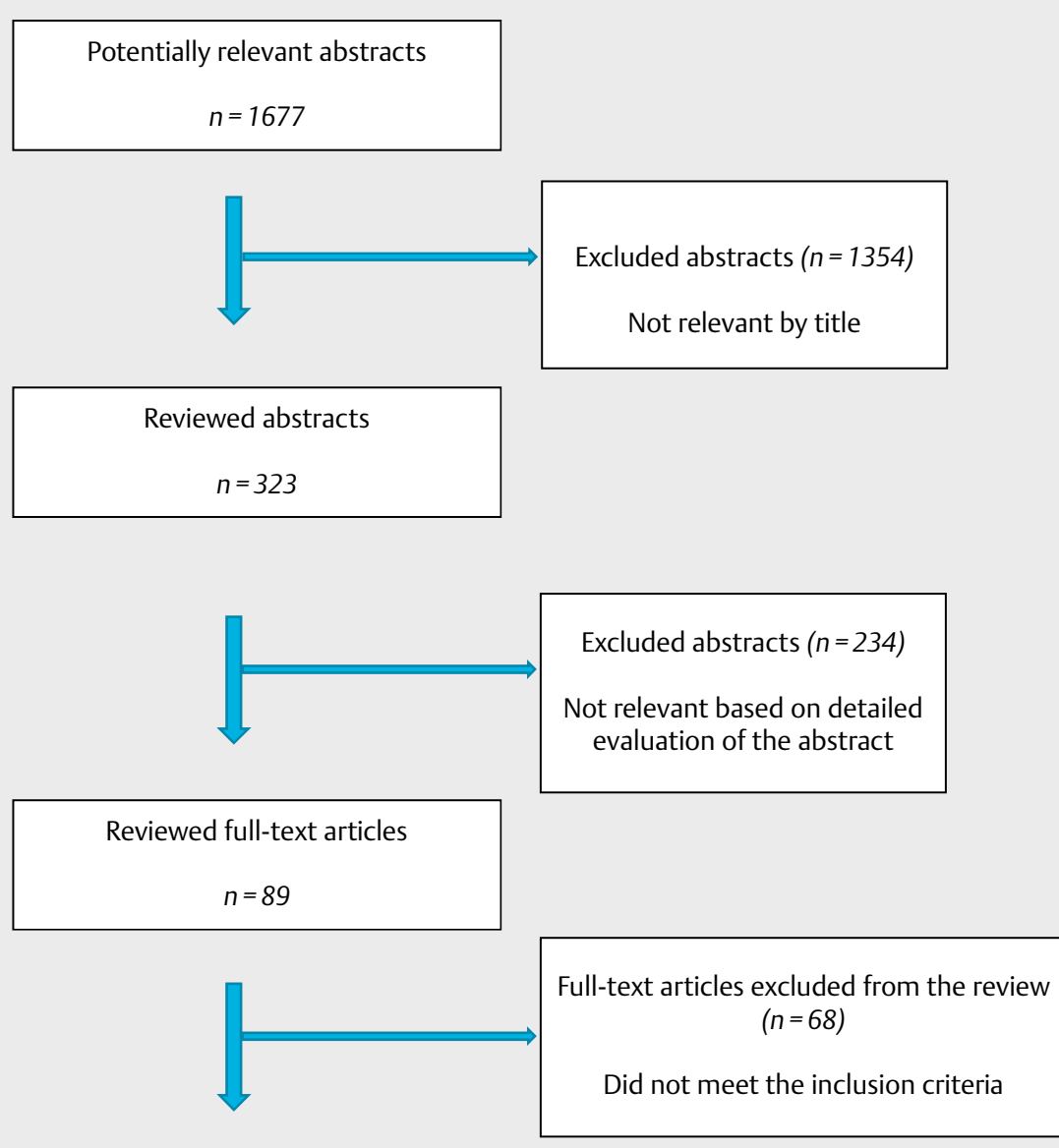

Articles included for analysis

$n=21$

- Fig. 1 Flow diagram of study selection for the systematic review.

and this was significantly higher compared to US, CT and CT-CT in the studies from period $1(19,21)$.

IOUS detected between 32 and $57 \%$ additional liver metastases compared to preoperative imaging in all studies in both periods $(19-22,25,34)$ ( Table 2).

\section{Per patient analysis}

8 studies compared the test performance of IOUS to the preoperative imaging modalities in a per patient analysis $(6,18,23,24,27$, $28,33,36)$ ( $\vee$ Table 3 ). IOUS showed a higher sensitivity and higher specificity (96-100\% and $98-100 \%$, respectively) compared to preoperative imaging (US and CE-CT) in the studies from both periods. In 2 of the studies IOUS showed a significantly higher sensitivity compared to preoperative US $(6,27)$. One study found the sensitivity of IOUS inferior compared to CE-CT (28) IOUS detected more patients with liver metastases when compared to preoperative US, CT and CE-CT $(33,36)$.

The PPV and NPV of IOUS were evaluated in 4 studies and a higher PPV and NPV (90-100\% and 89-100\%) compared to US and CE-CT were observed $(6,24,27,28)$ ( $\triangleright$ Table 3$)$.
The overall accuracy for IOUS was $98 \%$ and this was higher compared to US and CT-CT $(6,24,27)$. One study showed a significantly higher overall accuracy compared to US (27) ( $>$ Table 3). From period 1 , IOUS detected up to $9 \%$ additional patients with liver metastases compared to US, CT and CE-CT imaging in the studies (6, $18,23,24)$. One IOUS study did not find additional patients with liver metastases (28). In the studies from period 2, IOUS detected additional patients with liver metastases upto $14 \%$ of cases compared to preoperative US, CT and CE-CT imaging $(27,33,36)$ ( Table 3).

Overall, 5 studies from period 1 found a significantly higher sensitivity of IOUS (range 90-100\%) compared to preoperative imaging (range 41-91\%) (6, 19, 21, 22, 25).

3 studies found a significantly higher overall accuracy when comparing IOUS (94-99\%) to US (74-97\%), CT (75\%) and CE-CT (74\%) $(19,21,27)$. Only one of the more recent studies (period 2) reported on the sensitivity, specificity, PPV, NPV and overall accuracy and found IOUS superior compared to preoperative US (27).

One small, prospective trial reported the results of contrast-enhanced IOUS (CE-IOUS) using the microbubble agent SonoVue ${ }^{\circledR}$ 
- Table 1 Characteristics of included studies on IOUS and LUS $(n=19)$ and contrast-enhanced IOUS and LUS $(n=2)$.

\begin{tabular}{|c|c|c|c|c|c|c|c|}
\hline Study & Year & Design & $\begin{array}{l}\text { Preoperative } \\
\text { investigation }\end{array}$ & $\begin{array}{l}\text { Patients } \\
\text { n }\end{array}$ & $\begin{array}{l}\text { Histological } \\
\text { confirmation }\end{array}$ & Follow- up * & Grading \\
\hline \multicolumn{8}{|c|}{ Period 1 (Studies published before January 1,2005 ) } \\
\hline Boldrinil [18] & 1987 & Prospective $^{\mathrm{a}}$ & US/CT & 86 & Yes & No & +000 \\
\hline Machi al [19] & 1987 & Prospective $^{\mathrm{a}}$ & US/CE-CT & $84^{* *}$ & Yes & Yes & +000 \\
\hline Olsen A.K [20] & 1990 & Prospective ${ }^{a}$ & US & 213 & Yes & Yes & + ooo \\
\hline Machi al [21] & 1991 & Prospective ${ }^{a}$ & US/CT & 189 & Yes & Yes & + ooo \\
\hline Stadler [22] & 1991 & Prospective ${ }^{a}$ & US/CE-CT & 85 & Yes & No & +000 \\
\hline Stewart [23] & 1993 & Prospective ${ }^{\mathrm{a}}$ & US/CE-CT & 100 & Yes & Yes & +000 \\
\hline Paul [24] & 1994 & Prospective & US/CE-CT & 122 & Yes & Yes & ++00 \\
\hline Rafaelsen [25] & 1994 & Prospective, blindeda & US & 295 & Yes & Yes & +000 \\
\hline Takeuchi [6] & 1995 & Prospective & US & 119 & Yes & Yes & ++00 \\
\hline Marchesa [26] & 1996 & Prospective $^{b}$ & $\mathrm{CE}-\mathrm{CT}$ & 22 & Yes & No & +000 \\
\hline Carter [28] & 1996 & Prospective $^{\mathrm{a}}$ & US/CE-CT & 73 & Yes & Yes & +000 \\
\hline Goletti [29] & 1998 & Prospective ${ }^{b}$ & US/CE-CT & 33 & Yes & No & +000 \\
\hline Foley [30] & 1998 & Prospective ${ }^{b}$ & - & 13 & Yes & No & 0000 \\
\hline Hartley [31] & 2000 & Prospective ${ }^{b}$ & US/MRI & 76 & No & Yes & ++ oo \\
\hline Milsom [32] & 2000 & Prospective, blinded ${ }^{b}$ & CE-CT & 77 & No & Yes & +000 \\
\hline \multicolumn{8}{|c|}{ Period 2 (Studies published after January 1, 2005) } \\
\hline Study & Year & Design & $\begin{array}{l}\text { Preoperative } \\
\text { investigation }\end{array}$ & $\begin{array}{l}\text { Patients } \\
\mathrm{N}\end{array}$ & $\begin{array}{l}\text { Histological } \\
\text { confirmation }\end{array}$ & Follow- up ${ }^{*}$ & Grading \\
\hline Agrawal [33] & 2006 & Retrospective $^{a}$ & US/CT & 76 & Yes & Yes & + ooo \\
\hline Kulig [27] & 2007 & Retrospective, blindeda & US & 388 & Yes & Yes & +000 \\
\hline Mazzoni [34] & 2007 & Prospective, blinded ${ }^{a}$ & US/CE-CT & 167 & Yes & Yes & +000 \\
\hline Skrovina [35] & 2008 & Prospective ${ }^{\mathrm{b}}$ & US/CE-CT/MRI/PET & 70 & Yes & No & ++00 \\
\hline Shah [36] & 2010 & Prospective ${ }^{c}$ & CE-CT & 21 & No & Yes & +000 \\
\hline Itabashi [37] & 2014 & Retrospective $^{d}$ & $\mathrm{CE}-\mathrm{CT} / \mathrm{MRI}$ & 148 & Yes & Yes & ++ oo \\
\hline Total & & & & 2457 & & & \\
\hline \multicolumn{8}{|c|}{${ }^{*}$ Follow-up: Postoperative scans (UL, CT, CE-CT or MRI) after 3-6 months } \\
\hline \multicolumn{8}{|c|}{${ }^{* *} 8$ of the 84 patients had metachronous liver metastases } \\
\hline \multicolumn{8}{|c|}{ Underline: Trial with CRC patients without known synchronous liver metastases on preoperative imaging } \\
\hline \multicolumn{8}{|c|}{ a: Intraoperative ultrasound (IOUS), b: Laparoscopic ultrasound (LUS), c: Contrast-enhanced IOUS, d: Contrast-enhanced LUS } \\
\hline
\end{tabular}

and CE-IOUS provided a change in the diagnosis of the liver lesions in $20 \%$ of cases (36).

In both periods the treatment plan was changed to less extensive surgery or oncological therapy in $10-17 \%$ of the patients due to the IOUS findings $(22,24,25,27,34,36)$.

\section{Laparoscopic ultrasound (LUS)}

7 studies reported on the use of LUS in the detection of synchronous liver metastases during laparoscopic surgery of primary CRC $(26,29-32,35,37) .5$ studies were from period 1 and 2 studies from period $2(26,29-32,35,37)$ ( Table 4). Only one trial evaluated LUS in patients without known liver metastases (37). In 6 trials the findings of the preoperative imaging modalities (US, CT, CE-CT and MRI) were compared to LUS findings $(26,29,31,32$, $35,37)$.

\section{Per lesions analysis}

Only studies from period 1 included per lesion analyses. 2 studies compared the test performance of LUS to preoperative imaging modalities and one study to IOUS in per lesion analyses $(26,30,32)$. The sensitivity and specificity for LUS were evaluated in one study and were 80 and $91 \%$, respectively (30). The sensitivity and specificity were not calculated in the other studies, but LUS detected from 2 to $13 \%$ additional liver metastases when compared to preoperative CE-CT $(26,32)$.

\section{Per patient analysis}

4 studies compared the test performance of LUS in per patient analyses $(29,31,35,37)$. Of these, one study found LUS to have a higher sensitivity, specificity and overall accuracy $(100,100$ and $100 \%$, respectively) compared to preoperative CE-CT $(63,96$ and $88 \%$, 
- Table 2 Test performance of IOUS and preoperative imaging modalities of the liver in open CRC surgery; based on per lesion analysis.

\begin{tabular}{|c|c|c|c|c|c|c|c|c|}
\hline Study & Modality & Sensitivity (\%) & $\begin{array}{l}\text { Specificity } \\
\text { (\%) }\end{array}$ & PPV (\%) & NPV (\%) & $\begin{array}{l}\text { Overall } \\
\text { accuracy (\%) }\end{array}$ & $\begin{array}{l}\text { Number of } \\
\text { detected } \\
\text { metastases }\end{array}$ & $\begin{array}{l}\text { Additional } \\
\text { metastases } \\
\text { detected only } \\
\text { by IOUS (\%) }\end{array}$ \\
\hline \multicolumn{9}{|c|}{ Studies before 2005 (period 1) } \\
\hline $\begin{array}{l}\text { Machi [19] } \\
n=84\end{array}$ & $\begin{array}{l}\text { IOUS } \\
\text { US } \\
\text { CE-CT }\end{array}$ & $\begin{array}{l}97.8 p<0.01^{\mathrm{a}} \\
41.3 \\
47.8\end{array}$ & $\begin{array}{l}94.0 \\
95.5 \\
92.5\end{array}$ & $\begin{array}{l}91.8 \\
86.4 \\
81.5\end{array}$ & $\begin{array}{l}98.4 p<0.01^{a} \\
70.3 \\
72.1\end{array}$ & $\begin{array}{l}95.4 p<0.01^{a} \\
73.5 \\
74.3\end{array}$ & $\begin{array}{l}45 \\
19 \\
22\end{array}$ & 51 \\
\hline $\begin{array}{l}\text { Olsen A.K. [20] } \\
n=213\end{array}$ & $\begin{array}{l}\text { IOUS } \\
\text { US }\end{array}$ & $\begin{array}{l}98.3 \\
66.1\end{array}$ & & & & & $\begin{array}{l}354 \\
238\end{array}$ & 33 \\
\hline $\begin{array}{l}\text { Machi [21] } \\
n=189\end{array}$ & $\begin{array}{l}\text { IOUS } \\
\text { US } \\
\text { CT }\end{array}$ & $\begin{array}{l}93.3 p<0.001^{a} \\
41.3 \\
47.1\end{array}$ & $\begin{array}{l}94.7 \\
96.7 \\
94.1\end{array}$ & $\begin{array}{l}92.4 p<0.001^{a} \\
89.6 \\
84.5\end{array}$ & $\begin{array}{l}95.4 p<0.05^{a} \\
70.9 \\
72.2\end{array}$ & $\begin{array}{l}94.1 p<0.001^{a} \\
74.2 \\
75.0\end{array}$ & $\begin{array}{l}97 \\
43 \\
49\end{array}$ & 50 \\
\hline $\begin{array}{l}\text { Stadler [22] } \\
n=85\end{array}$ & $\begin{array}{l}\text { IOUS } \\
\text { US/CE-CT }\end{array}$ & $\begin{array}{l}89.9 p<0.001^{a} \\
48.5\end{array}$ & $\begin{array}{l}98.3 \\
93.3\end{array}$ & & & & $\begin{array}{l}62 \\
27\end{array}$ & 57 \\
\hline $\begin{array}{l}\text { Rafaelsen [25] } \\
n=295\end{array}$ & $\begin{array}{l}\text { IOUS } \\
\text { US }\end{array}$ & $\begin{array}{l}94.1 p<0.0001^{a} \\
63.7\end{array}$ & $\begin{array}{l}97.8 \\
92.0\end{array}$ & & & & $\begin{array}{l}192 \\
130\end{array}$ & 32 \\
\hline \multicolumn{9}{|c|}{ Study after 2005 (period 2) } \\
\hline $\begin{array}{l}\text { Mazzoni [34] } \\
n=167\end{array}$ & $\begin{array}{l}\text { IOUS } \\
\text { US } \\
\text { CE-CT }\end{array}$ & $\begin{array}{l}- \\
56 \\
49\end{array}$ & $\begin{array}{l}- \\
94 \\
92\end{array}$ & & & & $\begin{array}{l}84 \\
47 \\
41\end{array}$ & 44 \\
\hline \multicolumn{9}{|c|}{$\mathrm{n}$ : number of patients included in the study } \\
\hline
\end{tabular}

respectively) (29). The sensitivity, specificity and overall accuracy were not calculated in the other 2 studies from period 2, but LUS detected from 3 to $11 \%$ additional patients with liver metastases compared to US, CE-CT and MRI $(35,37)$ ( $\triangleright$ Table 4).

Neither $p$-values regarding the comparison of LUS and preoperative findings nor the PPV or NPV was reported in any of the trials.

One trial used contrast-enhanced LUS (CE-LUS) with a micro-bubble agent (Sonozoid $®$ ) and CE-LUS detected metastases not seen on the preoperative imaging modalities (CE-CT and MRI) [37].

One trial from period 1 evaluated the change in treatment plan (i. e., resectability of liver metastases) based on the additional findings of LUS, and LUS led to a change in $12 \%$ of the patients [29].

\section{Discussion}

\section{Detection of synchronous liver metastases with IOUS during primary CRC surgery}

The majority of the trials were from period 1 , and IOUS was mostly compared to preoperative ultrasound $(6,18-25,27,28)$. 6 trials showed a significant difference in sensitivity, PPV, NPV and overall accuracy in favor of IOUS regarding the detection of additional liver metastases when compared to preoperative ultrasound $(6,19,21$, $22,25,27)$. IOUS also had a higher specificity compared to preoperative ultrasound, but this was not statistically significant.

The trials included in this review span a very large time period, which led to the fact that many of them utilized quite poor comparators. This was particularly evident in the studies of period 1 . There- fore, the comparison of preoperative ultrasound and non-contrast-enhanced CT has become obsolete. Many of the trials in this review use these outdated preoperative imaging modalities (US and non-contrast $(\mathrm{CT}$ ), and $\mathrm{CT}$ scans nowadays are more sensitive when performed as multi-slice, multi-phase contrast-enhanced imaging. The current recommendation for preoperative imaging for CRC is CE-CT due to its better sensitivity and specificity compared to transabdominal ultrasound $(1,39,40)$.

2 studies from the same institution showed that IOUS had a significantly better test performance than preoperative CT and CE-CT $[19,21]$. Other trials showed the same trend regarding the number of additional detected liver metastases, but there was no information regarding $p$-values $(23,24)$. Only 1 of the 14 trials showed IOUS to be inferior to CE-CT [28], but there was no obvious explanation for this observation. The reported poor sensitivity and specificity of CT and CE-CT in studies from the early period were probably due to the fact that these scans were performed without contrast agents or with a CE-CT slice thickness of 8-10 mm (18, 19, 21, 23, 24). However, a similarly poor sensitivity was also noted in studies published more recently (34).

When comparing the 2 periods, IOUS detected $44 \%$ additional liver metastases ("per lesion analysis") in period 2 compared to $32-52 \%$ in the trials from period 1 . Looking at the "per patient analysis", there were a higher number of additional patients with liver metastases found (up to 14\%) in the trials from period 2 compared to the trials from period 1 (up to $9 \%$ ), even though preoperative US or (non-contrast) CT was the preferred standard in the latter period. It is important to note that despite the time-dependent im- 
- Table 3 Test performance of IOUS and preoperative imaging modalities of the liver in open CRC surgery; based on per patient analysis.

\begin{tabular}{|c|c|c|c|c|c|c|c|c|}
\hline Study & Modality & Sensitivity (\%) & $\begin{array}{l}\text { Specificity } \\
\text { (\%) }\end{array}$ & PPV (\%) & NPV (\%) & $\begin{array}{l}\text { Overall } \\
\text { accuracy } \\
(\%)\end{array}$ & $\begin{array}{l}\text { Number of } \\
\text { patients with } \\
\text { detected } \\
\text { metastases }\end{array}$ & $\begin{array}{l}\text { Additional patients } \\
\text { with metastases } \\
\text { detected only by } \\
\text { IOUS (\%) }\end{array}$ \\
\hline \multicolumn{9}{|c|}{ Studies before 2005 (period 1) } \\
\hline $\begin{array}{l}\text { Paul [24] } \\
n=122\end{array}$ & $\begin{array}{l}\text { IOUS } \\
\text { US } \\
\text { CE-CT }\end{array}$ & $\begin{array}{l}96 \\
76 \\
76\end{array}$ & $\begin{array}{l}98 \\
94 \\
90\end{array}$ & $\begin{array}{l}92 \\
76 \\
66\end{array}$ & $\begin{array}{l}99 \\
94 \\
94\end{array}$ & $\begin{array}{l}98 \\
90 \\
87\end{array}$ & $\begin{array}{l}25 \\
19 \\
19\end{array}$ & 5 \\
\hline $\begin{array}{l}\text { Carter }[28] \\
n=73\end{array}$ & $\begin{array}{l}\text { IOUS } \\
\text { US } \\
\text { CE-CT }\end{array}$ & $\begin{array}{l}77 \\
77 \\
94\end{array}$ & $\begin{array}{l}100 \\
100 \\
91\end{array}$ & $\begin{array}{l}100 \\
100 \\
89\end{array}$ & $\begin{array}{l}89 \\
85 \\
95\end{array}$ & & $\begin{array}{l}13 \\
13 \\
16\end{array}$ & 0 \\
\hline $\begin{array}{l}\text { Takeuchi [6] } \\
n=119\end{array}$ & $\begin{array}{l}\text { IOUS } \\
\text { US }\end{array}$ & $\begin{array}{l}100 p<0.01 \\
42\end{array}$ & $\begin{array}{l}98 \\
99\end{array}$ & $\begin{array}{l}90 \\
88\end{array}$ & $\begin{array}{l}100 \\
90\end{array}$ & $\begin{array}{l}98 \\
90\end{array}$ & $\begin{array}{l}19 \\
8\end{array}$ & 9 \\
\hline $\begin{array}{l}\text { Boldrinil } \\
{[18]} \\
n=86\end{array}$ & $\begin{array}{l}\text { IOUS } \\
\text { US } \\
\text { CT }\end{array}$ & & & & & & $\begin{array}{l}21 \\
16 \\
16\end{array}$ & 6 \\
\hline $\begin{array}{l}\text { Stewart [23] } \\
n=100\end{array}$ & $\begin{array}{l}\text { IOUS } \\
\text { US } \\
\text { CE-CT }\end{array}$ & & & & & & $\begin{array}{l}16 \\
10 \\
11\end{array}$ & 5 \\
\hline \multicolumn{9}{|c|}{ Studies after 2005 (period 2) } \\
\hline $\begin{array}{l}\text { Agrawal [33] } \\
n=76\end{array}$ & $\begin{array}{l}\text { IOUS } \\
\text { US } \\
\text { CT }\end{array}$ & & & & & & $\begin{array}{l}11 \\
0 \\
0\end{array}$ & 14 \\
\hline $\begin{array}{l}\text { Kuling [27] } \\
n=388\end{array}$ & $\begin{array}{l}\text { IOUS } \\
\text { US }\end{array}$ & $\begin{array}{l}99.1 p<0.05 \\
91.1\end{array}$ & $\begin{array}{l}98.5 p>0.05 \\
98.5\end{array}$ & $\begin{array}{l}99.1 p>0.05 \\
95.7\end{array}$ & $\begin{array}{l}98.5 p>0.05 \\
96.8\end{array}$ & $\begin{array}{l}98.9 p<0.05 \\
96.6\end{array}$ & $\begin{array}{l}247 \\
227\end{array}$ & 5 \\
\hline $\begin{array}{l}\text { Shah [36] } \\
n=21^{b}\end{array}$ & $\begin{array}{l}\text { IOUS } \\
\text { CE-CT }\end{array}$ & & & & & & $\begin{array}{l}4 \\
1\end{array}$ & 14 \\
\hline
\end{tabular}

provements in CE-CT, the detection of liver metastases less than $10 \mathrm{~mm}$ in diameter seems to remain a challenge [6, 23-25, 34].

The low number of publications $(n=4)$ in period 2 is a limit with respect to more exact conclusions regarding modern IOUS, but this observation probably just illustrates the widespread use of laparoscopic surgery in the treatment of CRC within this period.

Contrast-enhanced IOUS (CE-IOUS) increases the sensitivity for detecting liver metastases during liver surgery [38, 39], but only one trial using CE-IOUS during primary CRC resection was identified (36). The trial reported a change in the diagnosis of the liver lesions in $20 \%$ of cases, but only one malignant additional liver lesion was detected by CE-IOUS when compared to IOUS. Since only 21 patients were included, no firm conclusion can be drawn. There was a tendency towards CE-IOUS providing a higher sensitivity and specificity than non-contrast-enhanced IOUS, but there is a need for larger and controlled trials.

\section{Detection of synchronous liver metastases with LUS during primary CRC surgery}

Only 7 trials dealing with LUS as a screening modality for synchronous liver metastases during primary laparoscopic resection for colorectal cancer were found: 5 studies from period 1 and 2 from period $2(26,29-32,35,37)$. In the trials from period 1 , up to $9 \%$ additional patients with liver metastases were found during LUS $(29,31)$. This was comparable to the results from period 2 , where up to $11 \%$ additional patients were detected $(35,37)$.

The higher number of additional patients with liver metastases found in period 2 than in period 1 could be related to the fact that in period 1 most studies already included patients with some metastases. Hence, there were not many additional patients with metastases to be found, whereas the studies in period 2 also investigated series of patients starting with no apparent lesions, so that it was more likely to find additional patients with a few metastases.

In both periods, LUS detected more patients with liver metastases ("per patient" analysis) compared to the preoperative CE-CT and MRI scans. No "per lesion" analyses were found in the trials from period 2, but in a recently published meta-analysis MRI has an overall sensitivity of $78-86 \%$ and a specificity of $87 \%$ for detecting liver metastases in a "per lesion" analysis [40,41]. Contrast-enhanced MRI with liver-specific contrast agents has a significantly higher sensitivity regarding the detection of liver metastases than CE-CT and PET/CT, but not to IOUS $[5,41]$. This corresponds well 
- Table 4 Test performance of LUS and preoperative imaging modalities of the liver in laparoscopic CRC surgery; based on per lesion and per patient analysis

\begin{tabular}{|l|l|l|l|}
\hline \multicolumn{2}{|c|}{ Per lesion analysis } \\
\hline Study & $\begin{array}{l}\text { Imaging } \\
\text { modality }\end{array}$ & $\begin{array}{l}\text { Number of } \\
\text { detected } \\
\text { metastases }\end{array}$ & $\begin{array}{l}\text { Number of } \\
\text { metastases } \\
\text { detected only by } \\
\text { LUS (\%) }\end{array}$ \\
\hline
\end{tabular}

Studies before 2005 (Period 1)

\begin{tabular}{|c|c|c|c|}
\hline $\begin{array}{l}\text { Foley [30] } \\
n=13\end{array}$ & $\begin{array}{l}\text { LUS } \\
\text { IOUS }\end{array}$ & $\begin{array}{l}4 \\
5\end{array}$ & 0 \\
\hline $\begin{array}{l}\text { Marchesa [26] } \\
n=22\end{array}$ & $\begin{array}{l}\text { LUS } \\
\text { CE-CT }\end{array}$ & $\begin{array}{l}8 \\
7\end{array}$ & 13 \\
\hline $\begin{array}{l}\text { Milsom et al. } \\
{[32]} \\
n=77\end{array}$ & $\begin{array}{l}\text { LUS } \\
\text { CE-CT }\end{array}$ & $\begin{array}{l}51 \\
50\end{array}$ & 2 \\
\hline
\end{tabular}

Per patient analysis

\begin{tabular}{l|l|l|l|l}
\hline Study & Imaging & Number of & Number of patients \\
\hline
\end{tabular} modality patients with with metastases detected only detected by metastases LUS (\%)

Studies before 2005 (period 1)

\begin{tabular}{|l|l|l|}
\hline Goletti [29] & LUS & 8 \\
\hline$n=33$ & CE-CT & 5 \\
\hline Hartley [31] & LUS & 5 \\
$n=76$ & US & 0 \\
\hline & MRI & 2 \\
\hline
\end{tabular}

Studies after 2005 (period 2)

\begin{tabular}{|c|c|c|}
\hline $\begin{array}{l}\text { Skrovina [35] } \\
n=70\end{array}$ & $\begin{array}{l}\text { LUS } \\
\text { CE-CT }\end{array}$ & $\begin{array}{l}14 \\
6\end{array}$ \\
\hline $\begin{array}{l}\text { Itabashi [37] a } \\
n=148\end{array}$ & $\begin{array}{l}\text { LUS + CE- } \\
\text { LUS } \\
\text { CE-CT } \\
\text { MRI }\end{array}$ & $\begin{array}{l}0 \\
0\end{array}$ \\
\hline
\end{tabular}

a and CE-LUS: contrast enhanced LUS

with the LUS findings in the "per patient analysis", which showed a higher detection rate for liver metastases compared to preoperative MRI $[31,37]$.

PET/CT has an overall sensitivity of $66-86 \%$ and a specificity of $97 \%$ in a "per-lesion" analysis for detecting colorectal liver metastases [5, 40-42]. However, most of the studies evaluate changes in clinical management according to PET/CT rather than the diagnostic performance. $\mathrm{PET} / \mathrm{CT}$ has a higher sensitivity in detecting extra-peritoneal spread than CE-CT, but the exact role of PET/CT is still unclear due to the small number of studies $[41,43,44]$. The present literature search revealed no trials comparing the test performance of PET/CT and intraoperative ultrasound during primary CRC surgery.

There were only 2 trials from period 1 assessing LUS in a "per lesion" analysis (26, 32). They found up to $13 \%$ additional metastases compared to preoperative CE-CT. Contrast-enhanced LUS examination of the liver was only evaluated in one retrospective study suggesting an increased detection rate of liver metastases, but the results should be confirmed in larger prospective trials [37].

As seen with IOUS, LUS was especially effective in detecting liver metastases < $10 \mathrm{~mm}$ in diameter [29, 31, 32, 35, 37]. A standard abdominal CE-CT scan has an overall sensitivity for detecting colorectal liver metastasis of 74-83\% and a specificity of $59 \%$ in a "per lesion" analysis, and for lesions under $10 \mathrm{~mm}$ the mean sensitivity drops to $47 \%[40,42,45]$. The mean sensitivity for detecting liver metastases $<10 \mathrm{~mm}$ is $60 \%$ for $\operatorname{MRI}(40,42)$. This relates to the higher detection rate of small liver metastases found during IOUS and LUS compared to preoperative imaging (CE-CT and MRI), but the fact that there is no delay between the examination (IOUS/LUS) and surgery may have had an impact on the results.

Both the "per lesion" and the "per patient" analyses are faced with potential bias problems. Most of the included trials used the "per lesion" analysis, and this may infer bias in favor of intraoperative ultrasound (e.g., including patients with multiple liver metastases will increase the probability of finding additional metastases). Using a "per patient" analysis may also cause problems, since this kind of analysis does not count the number of lesions, and therefore may underestimate the value of intraoperative ultrasound. In the present review, most of the included patients had known liver metastases at the time of surgery, and this may also have helped the IOUS/LUS evaluation. Overall, the lack of blinded trials was prominent in this review ( $n=4,19 \%)$.

In almost half of the studies it was a radiologist with ultrasound expertise who performed IOUS, and this would undoubtedly increase the sensitivity of the ultrasound examination $[1,6,23-$ $26,28,32,35,36]$. Therefore, it is unclear whether it would be possible to reproduce the same results in a clinical setting where the surgeon performs the ultrasound examination.

\section{Clinical impact of IOUS and LUS during primary CRC resection}

A clinical impact, defined as a change in initial treatment strategy, was reported in 7 trials $(22,24,25,27,29,34,36)$. IOUS altered the surgical strategy or postoperative therapy in $10-15 \%$ of the patients included in period 1 trials, and in $14-17 \%$ of trials from period $2(22,24,25,27,34,36)$. In the trial concerning CE-IOUS, the contrast-enhanced examination altered the diagnosis of the liver lesions in $20 \%$ of the patients and altered treatment strategy in $14 \%$ (36). The change in the treatment strategy due to LUS was evaluated in one trial from 1998 and it showed a treatment change in $12 \%$ of the patients (29). Although not directly comparable, these studies suggest that the clinical impact of IOUS and LUS remains unchanged over time - even in light of more extensive liver resections being performed during the latest period. Again, the lack of prospective studies with clearly defined (impact) criteria and a gold standard makes it difficult to draw any firm conclusions.

Staging with laparoscopy and LUS during upper GI-tract cancer surgery is a well-established procedure especially in the assessment of the surgical treatment of colorectal liver metastases (CRLM) $[46,47]$. Several large studies have shown a significantly higher detection rate of CRLM using laparoscopy and LUS during CRLM surgery compared to preoperative imaging modalities [46, 48-50]. Based on this data, it is somewhat surprising that laparoscopy and LUS have not gained the same momentum during the introduction 
of laparoscopic resection of primary CRC, and a prospective randomized study evaluating the actual clinical impact of adding LUS to the standard evaluation program for these patients seems warranted.

\section{Limitations of this review}

In this review some of the included trials used outdated preoperative imaging modalities (especially in period 1) and reviews with such different comparators do not allow solid conclusions from a scientific point of view, although the results were quite clear.

3 retrospective studies were also included in the review, which is suboptimal, but the trials had a homogeneous patient population and a controlled design.

The report of accuracy data in some studies was not optimal. In fact, IOUS/LUS tended to become their own reference standard for the ultimate number of lesions, because no information regarding follow-up was given in the articles. In the majority of the trials there was no information regarding neoadjuvant or adjuvant chemotherapy, which could bias the true value of intraoperative ultrasound. In fact, if a lesion was missed but treated by chemotherapy, it would not manifest and the false-negative finding of intraoperative ultrasound was not demonstrated.

\section{Conclusion}

This systematic review showed that both IOUS and LUS had a higher detection rate regarding (unrecognized) synchronous liver metastases during primary colorectal cancer surgery, especially smaller liver metastases $<10 \mathrm{~mm}$ in diameter, when compared to US, CT, CE-CT and MRI. Contrast-enhanced IOUS and LUS showed a higher sensitivity and specificity for detecting liver metastases compared to non-enhanced IOUS and LUS. The majority of trials in this review were from period 1 (published before the January 1, 2005) and had an obsolete preoperative imaging evaluation for comparison. To assess the true value of intraoperative ultrasound, there is a need for larger, prospective controlled trials in a homogeneous patient population including optimal preoperative imaging and well-defined clinical impact criteria and a gold standard.

\section{Conflict of Interest}

The authors declare that they have no conflict of interest.

\section{References}

[1] van de Velde C], Boelens PG, Borras JM, Coebergh JW, Cervantes A, Blomqvist $L$ et al. EURECCA colorectal: multidisciplinary management: European consensus conference colon \& rectum. European journal of cancer 2014; 50: 1e-e34

[2] De Greef K, Rolfo C, Russo A, Chapelle T, Bronto G, Passiglia F et al. Multisciplinary management of patients with lives metastasis from colorectal cancer. World Journal of gastroentrology. 2016; 22: 7215-25

[3] Gl Cancer. [internet]. Year of Published 2013 [cited 01.06.2016]. Available from: www.GlCancer.dk/klinische retningslinier for kolorectal lever metastaser.
[4] Finlay IG, McArdle CS. Occult hepatic metastases in colorectal carcinoma. The British journal of surgery 1986; 73: 732-735

[5] Bonanni L, De'liguori Carino N, Deshpande R, Ammori B], Sherlock D], Valle JW et al. A comparison of diagnostic imaging modalities for colorectal liver metastases. European journal of surgical oncology: the journal of the European Society of Surgical Oncology and the British Association of Surgical Oncology 2014; 40: 545-550

[6] Takeuchi N, Ramirez JM, Mortensen N], Cobb R, Whittlestone T. Intraoperative ultrasonography in the diagnosis of hepatic metastases during surgery for colorectal cancer. International journal of colorectal disease 1996; 11: 92-95

[7] Machi J, Sigel B. Operative ultrasound in general surgery. American journal of surgery 1996; 172: 15-20

[8] Cervone A, Sardi A, Conaway GL. Intraoperative ultrasound (IOUS) is essential in the management of metastatic colorectal liver lesions. The American surgeon 2000; 66: 611-615

[9] Elias D, Sideris L, Pocard M, de Baere T, Dromain C, Lassau N et al. Incidence of unsuspected and treatable metastatic disease associated with operable colorectal liver metastases discovered only at laparotomy (and not treated when performing percutaneous radiofrequency ablation). Annals of surgical oncology 2005; 12 : 298-302

[10] Luck AJ, Maddern G]. Intraoperative abdominal ultrasonography. The British journal of surgery 1999; 86: 5-16

[11] Larsen LP, Rosenkilde M, Christensen H, Bang N, Bolvig L, Christiansen $\mathrm{T}$ et al. The value of contrast enhanced ultrasonography in detection of liver metastases from colorectal cancer: a prospective double-blinded study. European journal of radiology 2007; 62: 302-307

[12] Veldkamp R, Gholghesaei M, Bonjer HJ, Meijer DW, Buunen M, Jeekel ] et al. Laparoscopic resection of colon Cancer: consensus of the European Association of Endoscopic Surgery (EAES). Surgical endoscopy 2004; 18: 1163-1185

[13] Schwenk W, Haase O, Neudecker J, Muller JM. Short term benefits for laparoscopic colorectal resection. The Cochrane database of systematic reviews 2005 CD003145

[14] Kuhry E, Schwenk W, Gaupset R, Romild U, Bonjer J. Long-term outcome of laparoscopic surgery for colorectal cancer: a cochrane systematic review of randomised controlled trials. Cancer treatment reviews 2008; 34: 498-504

[15] Poon JT, Law WL. Laparoscopic resection for rectal cancer: a review. Annals of surgical oncology 2009; 16: 3038-3047

[16] Breukink S, Pierie J, Wiggers T. Laparoscopic versus open total mesorectal excision for rectal cancer. The Cochrane database of systematic reviews 2006 CD005200

[17] Balshem H, Helfand M, Schunemann HJ, Oxman AD, Kunz R, Brozek J et al. GRADE guidelines: 3 . Rating the quality of evidence. Journal of clinical epidemiology 2011; 64: 401-406

[18] Boldrini G, de Gaetano AM, Giovannini I, Castagneto M, Colagrande C, Castiglioni G. The systematic use of operative ultrasound for detection of liver metastases during colorectal surgery. World journal of surgery 1987; 11: 622-627

[19] Machi ], Isomoto H, Yamashita Y, Kurohiji T, Shirouzu K, Kakegawa T. Intraoperative ultrasonography in screening for liver metastases from colorectal cancer: comparative accuracy with traditional procedures. Surgery 1987; 101: 678-684

[20] Olsen AK. Intraoperative ultrasonography and the detection of liver metastases in patients with colorectal cancer. The British journal of surgery 1990; 77: 998-999

[21] Machi ], Isomoto H, Kurohiji T, Yamashita Y, Shirouzu K, Kakegawa T et al. Accuracy of intraoperative ultrasonography in diagnosing liver metastasis from colorectal cancer: evaluation with postoperative follow-up results. World journal of surgery 1991; 15: 551-556 discussion 7 
[22] Stadler ], Holscher AH, Adolf ]. Intraoperative ultrasonographic detection of occult liver metastases in colorectal cancer. Surgical endoscopy 1991; 5: 36-40

[23] Stewart PJ, Chu JM, Kos SC, Chapuis PH, Bokey EL. Intra-operative ultrasound for the detection of hepatic metastases from colorectal cancer. The Australian and New Zealand journal of surgery 1993; 63: 530-534

[24] Paul MA, Mulder LS, Cuesta MA, Sikkenk AC, Lyesen GK, Meijer S. Impact of intraoperative ultrasonography on treatment strategy for colorectal cancer. The British journal of surgery 1994; 81: 1660-1663

[25] Rafaelsen SR, Kronborg O, Larsen C, Fenger C. Intraoperative ultrasonography in detection of hepatic metastases from colorectal cancer. Diseases of the colon and rectum 1995; 38: 355-360

[26] Marchesa P, Milsom JW, Hale JC, O'Malley CM, Fazio VW. Intraoperative laparoscopic liver ultrasonography for staging of colorectal cancer. Initial experience. Diseases of the colon and rectum 1996; 39 (10 Suppl): S73-S78

[27] Kulig J, Popiela T, Klek S, Milanowski W, Kolodziejczyk P, Szybinski P et al. Intraoperative ultrasonography in detecting and assessment of colorectal liver metastases. Scandinavian journal of surgery: SJS: official organ for the Finnish Surgical Society and the Scandinavian Surgical Society 2007; 96: 51-55

[28] Carter R, Hemingway D, Cooke TG, Pickard R, Poon FW, McKillop JA et al. A prospective study of six methods for detection of hepatic colorectal metastases. Annals of the Royal College of Surgeons of England 1996; 78: 27-30

[29] Goletti O, Celona G, Galatioto C, Viaggi B, Lippolis PV, Pieri L et al. Is laparoscopic sonography a reliable and sensitive procedure for staging colorectal cancer? A comparative study. Surgical endoscopy 1998; 12 : 1236-1241

[30] Foley EF, Kolecki RV, Schirmer BD. The accuracy of laparoscopic ultrasound in the detection of colorectal cancer liver metastases. American journal of surgery 1998; 176: 262-264

[31] Hartley JE, Kumar H, Drew P], Heer K, Avery GR, Duthie GS et al. Laparoscopic ultrasound for the detection of hepatic metastases during laparoscopic colorectal cancer surgery. Diseases of the colon and rectum 2000; 43: 320-324 discussion 4-5

[32] Milsom JW, Jerby BL, Kessler H, Hale JC, Herts BR, O'Malley CM. Prospective, blinded comparison of laparoscopic ultrasonography vs. contrast-enhanced computerized tomography for liver assessment in patients undergoing colorectal carcinoma surgery. Diseases of the colon and rectum 2000; 43: 44-49

[33] Agrawal N, Fowler AL, Thomas MG. The routine use of intra-operative ultrasound in patients with colorectal cancer improves the detection of hepatic metastases. Colorectal disease: the official journal of the Association of Coloproctology of Great Britain and Ireland 2006; 8: 192-194

[34] Mazzoni G, Napoli A, Mandetta S, Miccini M, Cassini D, Gregori M et al. Intra-operative ultrasound for detection of liver metastases from colorectal cancer. Liver international: official journal of the International Association for the Study of the Liver 2008; 28: 88-94

[35] Skrovina M, Bartos J, Cech B, Velkoborsky M, Czudek S, Kycina R et al. Intra-operative liver ultrasound-a contribution to colorectal carcinoma staging. Acta chirurgica Belgica. 2008; 108: 508-512

[36] Shah AJ, Callaway M, Thomas MG, Finch-Jones MD. Contrast-enhanced intraoperative ultrasound improves detection of liver metastases during surgery for primary colorectal cancer. HPB: the official journal of the International Hepato Pancreato Biliary Association 2010; 12 : $181-187$
[37] Itabashi T, Sasaki A, Otsuka K, Kimura T, Nitta H, Wakabayashi G. Potential value of sonazoid-enhanced intraoperative laparoscopic ultrasonography for liver assessment during laparoscopy-assisted colectomy. Surgery today 2014; 44: 696-701

[38] Takahashi M, Hasegawa K, Arita J, Hata S, Aoki T, Sakamoto Y et al. Contrast-enhanced intraoperative ultrasonography using perfluorobutane microbubbles for the enumeration of colorectal liver metastases. The British journal of surgery 2012; 99: 1271-1277

[39] Arita J, Ono Y, Takahashi M, Inoue Y, Takahashi Y, Saiura A. Usefulness of contrast-enhanced intraoperative ultrasound in identifying disappearing liver metastases from colorectal carcinoma after chemotherapy. Annals of surgical oncology 2014; 21 (Suppl 3): S390-\$397

[40] Floriani I, Torri V, Rulli E, Garavaglia D, Compagnoni A, Salvolini L et al. Performance of imaging modalities in diagnosis of liver metastases from colorectal cancer: a systematic review and meta-analysis. Journal of magnetic resonance imaging: JMRI 2010; 31: 19-31

[41] Niekel MC, Bipat S, Stoker J. Diagnostic imaging of colorectal liver metastases with CT, MR imaging, FDG PET, and/or FDG PET/CT: a meta-analysis of prospective studies including patients who have not previously undergone treatment. Radiology 2010; 257: 674-684

[42] Bipat S, van Leeuwen MS, Comans EF, Pijl ME, Bossuyt PM, Zwinderman $\mathrm{AH}$ et al. Colorectal liver metastases: $\mathrm{CT}$, MR imaging, and PET for diagnosis-meta-analysis. Radiology 2005; 237: 123-131

[43] Lee JH, Lee MR. Positron emission tomography/computed tomography in the staging of colon cancer. Annals of coloproctology 2014; 30: 23-27

[44] Brush J, Boyd K, Chappell F, Crawford F, Dozier M, Fenwick E et al. The value of FDG positron emission tomography/computerised tomography $(\mathrm{PET} / \mathrm{CT})$ in pre-operative staging of colorectal cancer: a systematic review and economic evaluation. Health technology assessment 2011; 15: 1-192 iii-iv

[45] Grossmann I, Klaase JM, Avenarius JK, de Hingh IH, Mastboom W], Wiggers T. The strengths and limitations of routine staging before treatment with abdominal CT in colorectal cancer. BMC cancer 2011; 11: 433

[46] John TG, Greig JD, Crosbie JL, Miles WF, Garden OJ. Superior staging of liver tumors with laparoscopy and laparoscopic ultrasound. Annals of surgery 1994; 220: 711-719

[47] Machi J, Oishi AJ, Furumoto NL, Oishi RH. Intraoperative ultrasound. The Surgical clinics of North America 2004; 84: 1085-1111 vi-i

[48] Wiering B, Ruers T], Krabbe PF, Dekker HM, Oyen WJ. Comparison of multiphase CT, FDG-PET and intra-operative ultrasound in patients with colorectal liver metastases selected for surgery. Annals of surgical oncology 2007; 14: 818-826

[49] Pilkington SA, Rees M, Peppercorn D, John TG. Laparoscopic staging in selected patients with colorectal liver metastases as a prelude to liver resection. HPB: the official journal of the International Hepato Pancreato Biliary Association 2007; 9: 58-63

[50] Adam R, De Gramont A, Figueras ], Guthrie A, Kokudo N, Kunstlinger F et al. The oncosurgery approach to managing liver metastases from colorectal cancer: a multidisciplinary international consensus. The oncologist 2012; 17: 1225-1239 